\title{
Climate change-driven losses in ecosystem services of coastal wetlands: A case study in the West coast of Bangladesh
}

\author{
Seyedabdolhossein Mehvar ${ }^{\mathrm{a}, \mathrm{b}, *}$, Tatiana Filatova ${ }^{\mathrm{c}, \mathrm{d}}$, Motaleb Hossain Sarker ${ }^{\mathrm{e}}$, Ali Dastgheib ${ }^{\mathrm{b}}$, \\ Roshanka Ranasinghe $\mathrm{e}^{\mathrm{a}, \mathrm{b}, \mathrm{f}}$
}

${ }^{a}$ Department of Water Engineering and Management, University of Twente, P.O. Box 217, 7500 AE, Enschede, the Netherlands

${ }^{\mathrm{b}}$ Department of Water Science and Engineering, IHE Delft Institute for Water Education, P.O. Box 3015, 2601 DA, Delft, the Netherlands

${ }^{\mathrm{c}}$ Department of Governance and Technology for Sustainability, University of Twente, P.O. Box 217, 7500 AE, Enschede, the Netherlands

${ }^{\mathrm{d}}$ Faculty of Engineering and Information Technology, University of Technology Sydney, Sydney, NSW 2007, Australia

${ }^{\mathrm{e}}$ Centre for Environmental and Geographic Information Services (CEGIS), Dhaka, Bangladesh

${ }^{\mathrm{f}}$ Harbour, Coastal and Offshore Engineering, Deltares, P.O. Box 177, $2600 \mathrm{MH}$, Delft, the Netherlands

\section{A R T I C L E I N F O}

\section{Keywords:}

Climate change

Wetland ecosystems

Sea level rise

Sundarbans

Economic valuation

\begin{abstract}
A B S T R A C T
Climate change is globally recognized as one of the key drivers of degradation of coastal wetland ecosystems, causing considerable alteration of services provided by these habitats. Quantifying the physical impacts of climate change on these services is therefore of utmost importance. Yet, practical work in this field is fragmented and scarce in current literature, especially in developing countries which are likely to suffer most from the adverse climate change impacts. Using a coherent scenario-based approach that combines assessment of physical impacts with economic valuation techniques, here we quantify potential climate change driven losses in the value of wetland ecosystems services due to relative sea-level rise (RSLR)-induced inundation in the vulnerable Western coastal area of Bangladesh in 2100. The results show a small inundation area in 2100 under the three IPCC climate scenarios of RCP2.6 (with $0.25 \mathrm{~m}$ of RSLR), RCP6.0 (with $1.18 \mathrm{~m}$ of RSLR), and RCP8.5 (with $1.77 \mathrm{~m}$ of RSLR) for the coastal wetland ecosystems including the Sundarbans mangrove forest, neritic system and aquaculture ponds. In all scenarios, RSLR will drive a loss in the total value of ecosystem services such as provision of raw materials, and food provision, ranging from US\$ 0-1 million to US\$ $16.5-20$ million, respectively. The outcomes of this study reveal that RSLR-induced inundation on its own, is unlikely to be a major threat to the wetland ecosystems in Western coast of Bangladesh. This would suggest that other climate change impacts such as coastal erosion, increase in frequency of cyclone events, and sea temperature rise might be the likely primary drivers of change in the value of wetland ecosystems services in this area.
\end{abstract}

\section{Introduction}

Climate change (CC) is likely to intensify coastal hazards imposing significant challenges on coastal regions (Adger et al., 2005). Populated coastal areas located in low elevation zones are highly vulnerable to CC impacts - in particular - to sea-level rise (SLR) (Nicholls, 2004, 2015; Weisse et al., 2014; Spalding et al., 2014; Dasgupta et al., 2017) and extreme floods (Aerts et al., 2014; de Moel et al., 2015). As a result of these impacts, wetlands and corresponding ecosystems will likely lose their resilience, changing in functions and structures (Peñuelas et al., 2017). As the socio-economic well-being of coastal communities is dependent on the services that coastal ecosystems provide (Mehvar et al., 2018b), it is important to have a good understanding of potential CC impacts on the wetland ecosystems services (WES) in coastal areas.
Following the history of CC studies, an over-focused assessment of only the primary impacts of CC is seen in coastal and marine areas. These fundamental impacts comprise ocean acidification, rising mean oceans temperature and sea-level, alteration in precipitation patterns, changes in frequency and intensity of coastal storms, etc. (Pernetta, 1992; Scavia et al., 2002; Harley et al., 2006; Hoegh-Guldberg et al., 2007; Nicholls and Cazenave, 2010; Sumaila et al., 2011; Cheung et al., 2011; Spalding et al., 2014). Recent studies have explored quantitative assessment of CC impacts on coastal WES by presenting few applications mostly in localized case studies, analyzing the coastal habitat loss and resulting decrease in monetary value of WES. For example, Barange et al. (2017) report that due to AR5 carbon emission scenarios adopted by the Intergovernmental Panel on Climate Change (IPCC), over the 21st century, the monetary loss of carbon sequestration service of the

\footnotetext{
* Corresponding author. Department of Water Engineering and Management, University of Twente, P.O. Box 217, 7500 AE, Enschede, the Netherlands.

E-mail address: s.mehvar@utwente.nl (S. Mehvar).
} 
North Atlantic Ocean is estimated to range between US\$ $170-3000$ billion and US\$23-401 billion in mitigation and adaptation costs, respectively. Yoskowitz et al. (2017) also show that under the IPCC A1B SRES scenario and a maximum SLR of $0.69 \mathrm{~m}$, selected coastal ecosystem services (disturbance regulation, waste regulation, recreation, and aesthetics) provided by the fresh marshes in Galveston Bay, Texas, will potentially face losses of more than US\$ 40 million annually. Similar quantitative estimations of CC driven variation in the value of WES can be also seen in the studies conducted by Roebeling et al. (2013) for the entire Europe, and by Kuhfuss et al. (2016) for a case study in France.

Yet, such quantitative estimations are scarce in the literature, especially in developing countries where the primary data both on physical impacts and valuation are limited and difficult to obtain (Mehvar et al., 2018b). The potential repercussion of any CC driven variation in WES would be particularly high in developing countries due to the inherently low adaptation capacity, and the high dependency of local communities on WES. This study aimed to quantify the potential CC driven variations in the value of WES in the Western coast of Bangladesh as a case study.

Bangladesh is the 3rd most susceptible country to SLR in the World in terms of the number of people affected (Minar et al., 2013). Hence, the focus of this study was the relative sea-level rise (RSLR)-induced inundation. The term RSLR here, refers to the sum of mean sea-level rise and the rate of local land subsidence. The study area covers two wetlands: (1) an estuary containing the Sundarbans mangrove forest (SMF) adjacent to the marine area representing mangrove swamps and neritic ecosystems, and (2) the aquaculture lands located mostly in the Northern part of the SMF. The study area choice is also driven by the fact that the Western coastal area of Bangladesh contains the Sundarbans swamps, which is recognized as the richest natural forest and most economically valuable coastal ecosystem in Bangladesh (Mondal and Debnath, 2017). This region is widely threatened by CC impacts such as increasing the frequency and intensity of cyclones, erosion, SLR, salt water intrusion and inundation (Loucks et al., 2010; Minar et al., 2013; Payo et al., 2016; Dasgupta et al., 2017). The low-lying geography of the area, combined with high population density, lack of efficient infrastructural and institutional capacity predefines the high vulnerability, therein (Denissen, 2012).

\section{Methods}

\subsection{Study area}

The study area with a total extent of $13,000 \mathrm{~km}^{2}$ is situated in the Western coastal area of Bangladesh in the three districts of Khulna, Satkira and Bagerhat, containing the Sundarbans forest adjacent to the Bay of Bengal in the South. Fig. 1 shows the land use map of the study area representing estuarine river and aquaculture lands as the two dominant wetlands containing the SMF and neritic system which are the coastal ecosystems considered in this study.

The Sundarbans was originally measured about 200 years ago with an extent of $16,700 \mathrm{~km}^{2}$ (Mahadevia and Vikas, 2012; Mondal and Debnath, 2017), that has now dwindled to approximately one third of its original size. The Sundarbans has been threatened by several natural and human induced factors such as climate change impacts (e.g. sealevel rise), overexploitation of forest resources, changes in coastal land use, increased salinity level, etc. (Islam and Bhuiyan, 2018). The SMF is widely accepted to be the largest single patch of mangrove forest in the World (Das and Siddiqi, 1985; Ali, 1994; Iftekhar, 1999; Rahman, 2003; Biswas et al., 2007; Roy et al., 2013; Uddin et al., 2013; Payo et al., 2016). The part of this forest located in Bangladesh is about $6000 \mathrm{~km}^{2}$ (Uddin et al., 2013; Hossain et al., 2018), comprising of $4143 \mathrm{~km}^{2}$ of land area and $1874 \mathrm{~km}^{2}$ of water area (Dasgupta et al., 2018). Tidal creeks and mud flats are the main characteristics of the Sundarbans (Hazra et al., 2016). The majority of this region lies at elevations between $0.9 \mathrm{~m}$ and $2.1 \mathrm{~m}$ above mean sea-level (Iftekhar and Islam, 2004; Hazra et al., 2016).

The interior parts of the intertidal zone and mudflats govern the morphology of the SMF, which serves as a desirable habitat for about 300 species of flora and 425 species of fauna, some of which are being threatened and endangered (Biswas et al., 2007). The Sundarbans region is known for its unique biodiversity (Dasgupta et al., 2018), providing a large nursery area for birds and numerous species of small fishes, crabs, shrimps, reptiles, and mammals such as tigers. This natural environment contributes considerably to fishery (fishing and aquaculture) which is one of the major livelihoods in Bangladesh being threatened by CC impacts such as SLR and saline water inundation (Chand et al., 2012). Notably, the threat of SLR to the SMF is still unclear (Payo et al., 2016) and the potential resilience capacity of the Sundarbans swamps to a certain inundation regime (as referred to "elevation capital" by Lovelock et al., 2015) is highly uncertain. The inundation tolerance capacity which varies remarkably among mangrove species (Yang et al., 2013) depend on the tidal range, positive effects of sediment supply and mangroves response to the increase in water salinity. On the other hand, this threatening impacts of CC on fishery, and in particular on aquaculture, are also now being increasingly recognized (Chand et al., 2012). Aquaculture with an impressive growth rate of about $9 \%$ per year contributes more to fishery sector in Bangladesh, compared to capture fisheries with its $4 \%$ growth rate (DOF, 2010; Belton and Azad, 2012).

More than 3 million people living in Bangladesh benefit from the WES provided by the West coast of Bangladesh and, especially by the Sundarbans swamps (Giri et al., 2007). Apart from providing habitat for flora and fauna, the SMF also contributes to the wood-based industry in Bangladesh by providing raw materials such as timber, fuelwood and thatching. Tourism as a cultural service is another service provided by the SMF (Hazra et al., 2016) due to the aesthetic and recreational value of its scenic landscapes for local and foreign visitors. The tourism industry has been improving over the years in the West coast of Bangladesh as a result of an increase in organized recreational tours and improved tourism facilities (Uddin et al., 2013).

\subsection{Methodology}

To quantify potential CC driven damages to the WES in the West coast of Bangladesh, the three-step methodological approach presented by Mehvar et al. (2018b) was applied. First, by employing standard economic valuation techniques, the present monetary value of WES was estimated using the original field work undertaken for this study. Secondly, using a scenario-based approach grounded in expert knowledge and secondary data from a thorough literature review, the potential impacts of RSLR-induced inundation on the pre-valued WES were identified for the year 2100 under three IPCC climate change scenarios (RCPs 2.6, 6.0 and 8.5). Finally, the resulting losses of WES were quantified by combining the results of previous two steps.

\subsubsection{Step 1 - current status: valuation of WES}

In the first step of this study, standard economic techniques (i.e. contingent valuation, market price and net factor income) were applied for estimating the present value of WES currently provided by the SMF, neritic system and aquaculture lands. In this study, aquaculture lands together with two natural ecosystems (mangrove forest and neritic system) were considered as one consistent system named "wetland ecosystems". From a variety of services which are provided by wetland ecosystems in Bangladesh (e.g. flood control, erosion stabilisation, climate regulation service such as carbon sequestration, etc.), here four WES were considered. The assessment of other important services were excluded due to limitation in data and resources. The four considered WES are recreation or tourism, food provision (fish and other marine species), provision of raw materials (timber and fuelwood), and art value. Valuation of these services was described in detail in the 


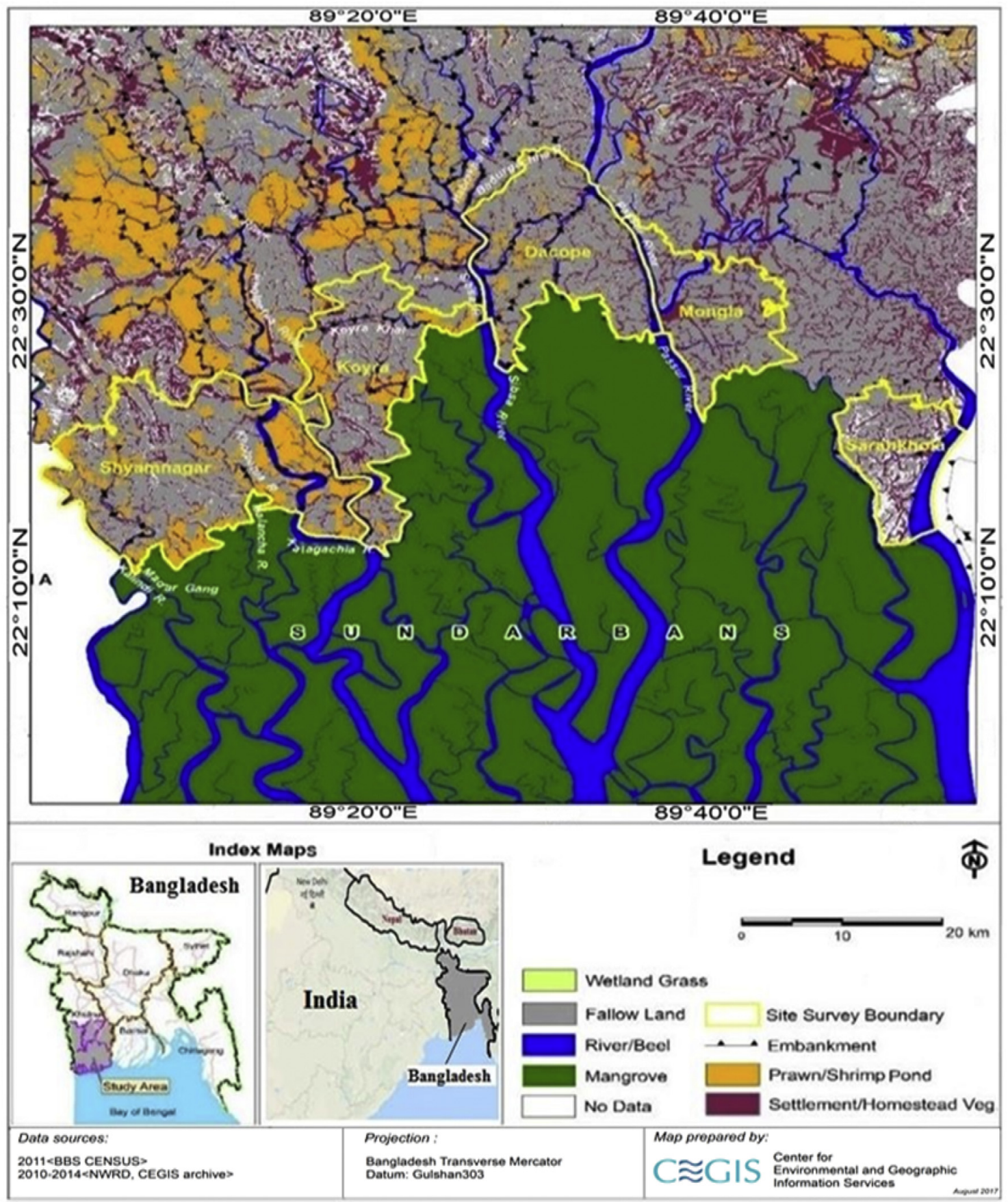

Fig. 1. Study area showing the land use information, and the boundary of data collection sites in yellow. Source: CEGIS. (For interpretation of the references to colour in this figure legend, the reader is referred to the Web version of this article.)

Supplementary Material - section 1, which was adapted from the similar approaches used by Van Beukering and Wolfs (2012), Schep et al. (2012), Schep et al. (2013), and Van de Kerkhof et al. (2014b). More information on the economic valuation of coastal ecosystem services including the best available practices can be found in Mehvar et al. (2018a).

2.2.2. Step 2 - physical impacts: identifying potential impacts of RSLRinduced inundation on WES by 2100

2.2.2.1. Development of inundation scenarios. In this step, first the extent of the inundated area due to RSLR in 2100 (relative to 2008) was determined along the West coast of Bangladesh for the three IPCC scenarios of RCP2.6, RCP6.0 and RCP8.5. These three RSLR scenarios developed for the study area are based on different local estimates of RSLR reported by IHE (2016), including a local land subsidence (LS) rate of $8.8 \mathrm{~mm} /$ year $(81 \mathrm{~cm}$ by 2100 ) for the Western coast derived from Brown and Nicholls (2015) and Roy et al. (2017).

Table 1 shows the calculated RSLR by 2100 including and excluding land subsidence for each RCP. Notably, in order to encapsulate the largest possible difference in the extent of inundated area, here the maximum variation of RSLR was used by considering lower and upper projections for the scenarios RCP 2.6, RCP 6.0 and RCP 8.5 while selectively including or excluding the land subsidence (since the future land subsidence rates are uncertain over the time scale of this study). This resulted in the development of three scenarios A, B, and C, representing each RCP indicated in Table 1. 
Table 1

Estimation of RSLR (m) and corresponding inundated area (Ha) by 2100 for the three RCPs considered in this study.

\begin{tabular}{llll}
\hline Parameter & \multicolumn{2}{l}{ Scenarios } & \\
\cline { 2 - 4 } & $\mathrm{A}^{\mathrm{a}}$ & $\mathrm{B}^{\mathrm{b}}$ & $\mathrm{C}^{\mathrm{c}}$ \\
\cline { 2 - 4 } & $\mathrm{RCP} 2.6$ & $\mathrm{RCP} 6.0$ & RCP 8.5 \\
\hline SLR (m) & 0.25 & 0.37 & 0.96 \\
LS (m) & - & 0.81 & 0.81 \\
RSLR (m) & 0.25 & 1.18 & 1.77 \\
Inundated area (Ha) & 16,000 & 61,200 & 80,500 \\
\hline
\end{tabular}

a Low scenario - Low SLR projection, no land subsidence.

b Moderate scenario - Low SLR projection, including land subsidence.

c Worst case scenario - High SLR projection, including land subsidence.

The inundated area due to the above computed RSLR was determined by using the most recent digital elevation map (DEM) of Bangladesh coastal area which is available with a spatial resolution of $30 \mathrm{~m}$ (https://earthexplorer.usgs.gov). Fig. 2 shows the inundation area determined by using ArcGis and a bath tub approach corresponding to the three developed scenarios A, B, and C.

2.2.2.2. Potential impacts of RSLR-induced inundation on WES in 2100. SLR can physically affect the coastal area by flooding and submerging ecosystems as an immediate effect, as well as erosion as a longer term effect (Nicholls and Cazenave, 2010). In this study, only the impacts of inundation due to RSLR on WES were considered, implying that increasing water salinity as a side effect of inundation was also considered as a threat to the WES.

To identify the potential impact of RSLR-induced inundation on WES, here a "what if scenario" approach was used, combined with secondary data from the literature. In this approach, related attributes for each WES were defined to analyse how inundation can potentially affect each of these attributes. For this analysis, depending on each service, its attributes and the 2100 inundation scenario, the impacts were quantified by assigning a range of change for each attribute, resulting in changes of WES value for the three RCPs. Therefore, by considering an impact indication, a 10\% increase or decrease in the value of attributes was represented for each + or - sign, respectively. This implies different ranges of change as $0 \%-10 \%, 11 \%-20 \%, 21 \%-30 \%$, $31 \%-40 \%$, corresponding to the assigned impact indications from one to four $+/-$ signs.
For two services (food provision, and art), local fishermen and experts who deal with art works were interviewed to elicit their opinions regarding the likely future changes of wetland ecosystems due to inundation. For the two other services (provision of raw materials, and tourism), a "what if scenario" was considered by which potential losses of these two services were hypothetically assumed, depending on the extent of inundated area in each scenario. It should be emphasized that, in this study the wetland ecosystems were considered as one system. Therefore, the impacts of RSLR-induced inundation on each of the SMF, aquaculture ponds, and marine area were not separately assessed, since the limited available data did not allow the evaluation of these impacts on the share of services provided by each wetland ecosystem. This qualitative assessment is described in detail for each service as follows:

2.2.2.2.1. Impacts on food provision service (fish and marine species). CC can potentially affect the fishery industry and the lives of fishing communities by increasing the frequency of storm events (Minar et al., 2013), and by SLR causing wetland submergence and salt intrusion. These impacts result in changing the food provision service provided by the neritic system (Bay of Bengal) and the SMF (i.e. two coastal ecosystems considered), and aquaculture fish ponds (i.e. manmade coastal wetland), which are situated in the North West of the SMF.

Here, we relied on the following literature for the basis of analysing the primary CC impacts on fishery: Goldes et al. (1988); Waters (1995); Henley et al. (2000); Harley et al. (2006); Portner and Knust (2007); MAB (2009); Cochrane et al. (2009); Mohanty et al. (2010); Sumaila et al. (2011); Williams and Rota (2010); and Mahadevia and Vikas (2012). Following this literature, different fishery related variables, which can potentially be affected by RSLR-induced inundation were identified. For example, distribution pattern and fish abundance can potentially be altered due to climate change impacts such as water temperature rise, changes to the ocean chemistry, ocean acidification, expansion of oxygen minimum zones, and climate-induced changes in hydrography (Portner and Knust, 2007; Mohanty et al., 2010; Sumaila et al., 2011). In addition, flooding of low lying areas due to SLR may provide an ideal habitat for the fish community due to the occurrence of salt water (MAB, 2009; Williams and Rota, 2010). Since the literature mentioned above do not specifically assess the inundation impacts on fishery due to SLR, here it was used as a basis to further develop the scenario-based approach used in this study, by considering a number of fishery-related variables that can potentially be affected by inundation.

After identifying the variables, the likely impacts of inundation on these variables were identified by eliciting local fishermen's opinions

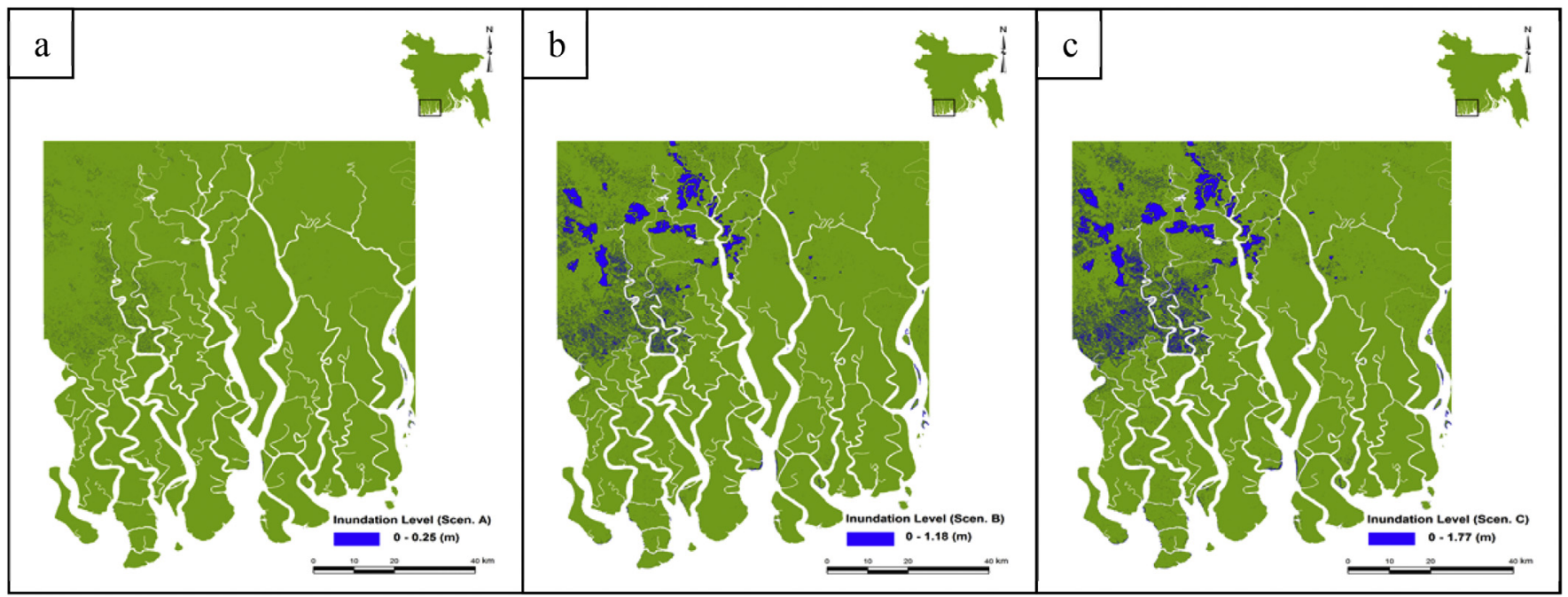

Fig. 2. Extent of the inundation area in blue for each scenario in 2100; (a) Scenario A with $0.25 \mathrm{~m}$ of RSLR; (b) Scenario B with $1.18 \mathrm{~m}$ of RSLR; (c) Scenario C with $1.77 \mathrm{~m}$ of RSLR. (For interpretation of the references to colour in this figure legend, the reader is referred to the Web version of this article.) 
(as an average magnitude, rounded off to our impact indication ranges), derived from the consultations and interviews with 80 randomly selected fishermen that were conducted individually and in group conversations. To this end, a qualitative assessment was conducted and impact indications were assigned to each variable, depending on the interview results and the extent of inundated area. The role of these impacts was linked to the producer surplus ${ }^{1}$ value of the food provision service, and the potential change in the value was ultimately quantified by summing the loss values estimated for each fishery-related variable.

2.2.2.2.2. Impacts on recreation/tourism service. Changes in the value of recreation or tourism service, provided mainly by the SMF and marine area, and to a smaller extent by the aquaculture lands, were estimated by assessing the potential impacts of RSLR-induced inundation on the producer surplus ${ }^{2}$ value of this service. To this end, eight tourism-related attributes were considered as stated by the visitor interviews in a custom-designed questionnaire, in which the visitors were asked to rank their preferred aspects (among the attributes) for which they visited the study area. Here, it was aimed to include the possible attributes considered as "the most enjoyed aspects" that directly or indirectly may attract the visitors to visit the study site. However, an extra option was added to the attributes as "other, specify", in case the visitors would like to state any other attribute/ aspect as their reason/motivation to visit the area. These attributes include tranquillity, natural landscape, friendly local people, safety, welfare facility for visitors, watching bird/live species, enjoying the beach area, and climate. The results represent each attribute with a weighted contribution level (as a percentage) to the total pre-estimated producer surplus value.

The total RSLR-induced inundation impact on recreation value was ultimately identified by assigning the quantitative impact indication (as defined before) to each (weighted) recreational attribute which varies for each inundation scenario. The hypothetical assignation of impact indications to the recreation service was necessary due to the scarcity of data and the lack of a similar application/methodology for conducting quantitative assessments.

2.2.2.2.3. Impacts on art service. To estimate the changes to art service provided by the SMF, marine area and aquaculture lands, first the art-related attributes were determined including coastal landscape as well as flora and fauna. Further, a range of scenarios of negative impacts $^{3}$ of inundation (by assigning the pre-defined impact indications) were presented to randomly selected artists and experts who deal with the art works (paintings, photos, etc.) in five different locations in the study area. Through this consultation and scenario-based approach, the ultimate negative impact was identified (as an average magnitude, rounded off to our impact indication ranges) by eliciting expert opinions on changes in art related attributes (i.e. coastal landscape, flora and fauna) which was different for each inundation scenario.

2.2.2.2.4. Impacts on provision of raw materials service (timber and fuelwood). Submergence of mangroves below mean sea-level (MSL) together with the impacts of soil and river salinity are the main factors that govern the loss of merchantable wood volume (adapted from Chaffey et al., 1985; Minar et al., 2013). Similar to the art value assessment, there is no established approach to quantify the inundation driven losses of the wood sources provided by the SMF. Therefore, here, a scenario-based approach was used, in which, depending on the extent of inundated area and lost mangrove area, different negative impact

\footnotetext{
${ }^{1}$ Total fishery value is calculated by estimating the producer surplus (PS) value, representing the net revenue generated by the fishery industry (see more details in Supplementary material).

${ }^{2}$ Total tourism value is calculated by estimating the producer surplus (PS) value, representing the net revenue generated by the visitors (see more details in Supplementary material).

${ }^{3}$ The data for such losses are currently unavailable. Thus, these assessments of the share of losses on art-related attributes could be considered as scenarios.
}

indications were considered on the wood market value. Notably, due to existence of the embankments which are partially located along the Northern boundary of the SMF, here a moderate level of landward migration of mangrove swamps was assumed, accommodating more space for this ecosystem to migrate while inundation occurs. This would imply consideration of more conservative impact indications for quantifying potential changes in the value of raw materials provided by the SMF due to likely effects of RSLR-induced inundation by 2100 .

\subsubsection{Step 3 - monetizing climate change impacts: quantifying the monetary changes in the WES value}

In the third and final step of the methodology used here, the environmental losses for each RCP were quantified by using the results of environmental impact identification (section 2.2.2), combined with the present monetary value of WES estimated in section 2.2.1. The final loss values were estimated in terms of present value (PV) of money (in 2017 price) implying that the discounting rate $^{4}$ was assumed to be zero, meaning that the current value of money was assumed to be the same as that in future.

\section{Results}

The results are presented below in two parts; (1) Present monetary value of WES; and (2) Potential losses in the value of WES due to RSLRinduced inundation by the year 2100 under three RCPs.

\subsection{Present-day value of WES}

Table 2 shows a summary of the present WES value of the Western coast of Bangladesh, which was estimated in million (MM) Bangladeshi Taka (BDT) and US Dollars per hectare ${ }^{5}$ (with the exchange rate of December 2017). According to the results, food provision (in terms of fish and marine species) represents the highest WES value estimated at 135 US\$/Ha. Provision of raw materials represents the second most valuable WES at 27 US\$ per hectare of the mangrove area of the Sundarbans, followed by recreation service (1.7 US $\$ / \mathrm{Ha}$ ), while art value represents only $0.01 \mathrm{US} \$ / \mathrm{Ha}$ in the study area. These derivation of estimates are described in detail for each WES in Supplementary material.

\subsection{Changes in the value of WES due to RSLR-induced inundation in 2100}

\subsubsection{Changes in the food provision value (fish and marine species)}

Table 3 shows the identification of potential impacts of inundation on fishery industry for each considered RSLR scenario, leading to changes in the value of food provision service provided by the wetland ecosystems in the study area. Expected inundation impacts were justified for each variable as indicated in Table 3 (adapted from Mehvar et al., 2018b).

Since the producer surplus represents the net revenue (gross revenue subtracted by the costs) generated by the fishery industry, in this analysis, the likely inundation impacts on catch volume, and market price as well as fishing and adaptation costs were considered. By identifying these impacts, resulting changes in the food provision service were quantified (see Table 4). For example, inundation increases the extent of natural nursery habitat for fishes, resulting in a likely

\footnotetext{
${ }^{4}$ In economic analysis, discounting a value refers to an estimate of the current value of future sum of money which decreases over time by using a discount rate.

${ }^{5}$ The estimation of raw materials value (timber and fuelwood) was considered only for the mangroves area of the Sundarbans with extent of $3778 \mathrm{~km}^{2}$, according to Payo et al. (2016), while the value of other three services were estimated per hectare of the whole wetland ecosystems considered as the SMF, neritic system and aquaculture lands with total size of $8300 \mathrm{~km}^{2}$.
} 
Table 2

Summary of the present value of WES in the Western coast of Bangladesh.

\begin{tabular}{|c|c|c|c|}
\hline WES & Estimated value (MM. BDT) & Estimated value (BDT/Ha) & Estimated value (US\$/Ha) \\
\hline Food provision (fish and marine species) & 9250 & 11,150 & 135 \\
\hline Raw materials (timber and fuelwood) & 856 & 2265 & 27 \\
\hline Recreation/tourism & 120 & 145 & 1.7 \\
\hline Art & 0.62 & 0.75 & 0.01 \\
\hline
\end{tabular}

Table 3

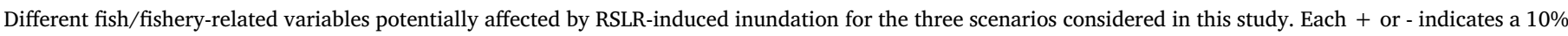
increase or decrease in the characteristics of variables compared to present. NK: Not known.

\begin{tabular}{|c|c|c|c|c|}
\hline \multirow[t]{2}{*}{ Fish/fishery related variable } & \multicolumn{3}{|c|}{ Potential impact of inundation } & \multirow[t]{2}{*}{ Expected inundation effect } \\
\hline & Scen. A & Scen. B & Scen. C & \\
\hline $\begin{array}{l}\text { Primary \& secondary } \\
\text { production }\end{array}$ & + & ++ & +++ & $\begin{array}{l}\text { Due to the increase of vertical mixing, more nutrients are likely to be supplied. Ideal situation is created } \\
\text { for breeding and oviposition, as larger nursery area is developed. }\end{array}$ \\
\hline Distribution/migration pattern & NK & NK & NK & $\begin{array}{l}\text { Unknown due to interaction of diverse variables such as water temperature, salinity, vertical mixing rates } \\
\text { and wind driven circulation. }\end{array}$ \\
\hline Abundance & + & ++ & +++ & Larger water body and nursery area will provide more nutrients. \\
\hline Health status & - & - &.- & Increased turbidity, probability of having (respiratory) diseases for species. \\
\hline Food web & + & ++ & +++ & Increased zooplanktonic organisms and nutrients supply. \\
\hline Nursery habitat & + & ++ & +++ & Due to the creation of larger (natural) water bodies. \\
\hline $\begin{array}{l}\text { Fish ponds \& fishing } \\
\text { community }\end{array}$ & - & $-\cdots$ & $\ldots$ & Due to probability of considerable damage to the fish ponds while inundation occurs. \\
\hline
\end{tabular}

Table 4

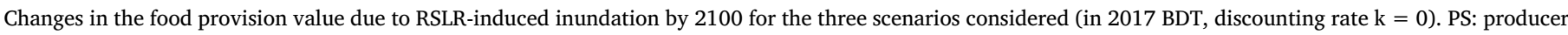

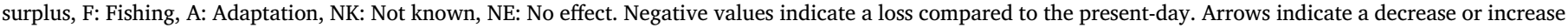
in the magnitude of catch volume, market price, fishing and adaptation costs due to the impact of inundation on the corresponding variable.

\begin{tabular}{|c|c|c|c|c|c|c|c|c|c|}
\hline \multirow[t]{2}{*}{ Fish/fishery related variable } & \multirow{2}{*}{$\begin{array}{l}\text { Catch } \\
\text { volume }\end{array}$} & \multirow{2}{*}{$\begin{array}{l}\text { Market } \\
\text { price }\end{array}$} & \multicolumn{2}{|c|}{ Cost } & \multirow{2}{*}{$\begin{array}{l}\text { Effect on producer } \\
\text {-surplus (PS) }\end{array}$} & \multirow{2}{*}{$\begin{array}{l}\text { Contribution to the PS } \\
\text { value }\end{array}$} & \multicolumn{3}{|c|}{ Change in the food provision value (MM. BDT) } \\
\hline & & & $\mathrm{F}$ & A & & & Scen. A & Scen. B & Scen. C \\
\hline $\begin{array}{l}\text { Primary \& secondary } \\
\text { production }\end{array}$ & $\uparrow$ & $\downarrow$ & $\downarrow$ & $\uparrow$ & $\mathrm{NE}$ & $10 \%$ & $\mathrm{NE}$ & $\mathrm{NE}$ & $\mathrm{NE}$ \\
\hline Distribution/migration & NK & NK & NK & NK & NK & $10 \%$ & NK & NK & NK \\
\hline Abundance & $\uparrow$ & $\downarrow$ & $\downarrow$ & $\uparrow$ & $\mathrm{NE}$ & $10 \%$ & $\mathrm{NE}$ & $\mathrm{NE}$ & $\mathrm{NE}$ \\
\hline Health status & $\downarrow$ & $\uparrow$ & $\uparrow$ & $\uparrow$ & $\downarrow$ & $10 \%$ & - $(0-92)$ & - (101-185) & - (194-277) \\
\hline Food web & $\uparrow$ & $\downarrow$ & $\downarrow$ & $\uparrow$ & $\mathrm{NE}$ & $10 \%$ & $\mathrm{NE}$ & $\mathrm{NE}$ & $\mathrm{NE}$ \\
\hline Nursery habitat & $\uparrow$ & $\downarrow$ & $\downarrow$ & $\uparrow$ & $\mathrm{NE}$ & $25 \%$ & $\mathrm{NE}$ & $\mathrm{NE}$ & $\mathrm{NE}$ \\
\hline $\begin{array}{l}\text { Fish ponds \& fishing } \\
\text { community }\end{array}$ & $\downarrow$ & $\uparrow$ & $\uparrow$ & $\uparrow$ & $\downarrow$ & $25 \%$ & $-(0-231)$ & - (717-925) & - (1180-1387) \\
\hline Total change & & & & & & & $-(0-323)$ & - (818-1110) & $-(1374-1664)$ \\
\hline
\end{tabular}

increase in catch volume, and hence lower market price. Therefore, producer surplus is expected to remain constant, due to the opposite effects of gross revenue and costs which will neutralize each other.

Changes in the food provision value due to RSLR-induced inundation was ultimately calculated as a range for each variable by using potential impact indications (Table 3), when the appropriate 'contribution to the producer surplus value (\%)'was multiplied by the pre-estimated (present-day) 'producer surplus' value. The total change was finally calculated by summing the changes of producer surplus associated with each variable, resulting in losses of 0-323 million BDT (US\$ 0-3,800,000), 818-1110 million BDT (US\$ 9,800,000-13,300,000), and 1374-1664 million BDT (US\$ 16,500,000-20,000,000) for scenarios A, B, and C, respectively.

\subsubsection{Changes in the recreation/tourism value}

Fig. 3 shows the results of ranking eight tourism related attributes by visitors, indicating that natural landscape and climate were selected respectively as the most and least favoured attributes. This ranking indicated by percentage was then taken to be representative of the contribution level of each attribute to the total pre-estimated presentday recreation value.

Table 5 presents the analysis of RSLR-induced inundation impacts

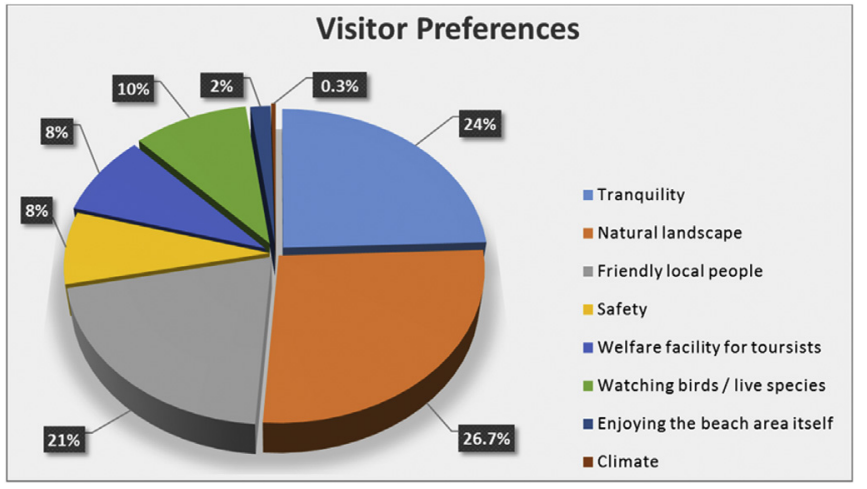

Fig. 3. Contribution of each recreational attribute to the total tourism value as indicated by visitors through ranking of their preferred attributes.

on recreation value indicating that inundation may potentially affect some of the recreational attributes (e.g. natural landscape, welfare facility for visitors), while it may impose no impact on some others (e.g. climatic condition). The potential future change in the value of each attribute was calculated by multiplying potential impact indications 
Table 5

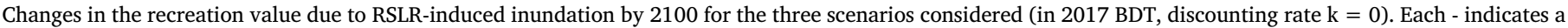
$10 \%$ decrease in the characteristics of the attributes compared to present. Negative values indicate a loss compared to the present-day. NE: No effect.

\begin{tabular}{|c|c|c|c|c|c|c|c|}
\hline \multirow[t]{2}{*}{ Tourism/recreational attribute } & \multicolumn{3}{|c|}{ Potential impact of inundation } & \multirow[t]{2}{*}{ Contribution to the PS value } & \multicolumn{3}{|c|}{ Change in the recreation value (MM. BDT) } \\
\hline & Scen. A & Scen. B & Scen. C & & Scen. A & Scen. B & Scen. C \\
\hline Tranquillity & - & - & $\ldots$ & $24 \%$ & $-(0-2.9)$ & - $(3.1-5.7)$ & $-(6-8.6)$ \\
\hline Natural landscape & - & -- & $-\ldots$ & $26.7 \%$ & $-(0-3.2)$ & $-(3.5-6.4)$ & $-(6.7-9.6)$ \\
\hline Friendly local people & $\mathrm{NE}$ & $\mathrm{NE}$ & $\mathrm{NE}$ & $21 \%$ & $\mathrm{NE}$ & $\mathrm{NE}$ & $\mathrm{NE}$ \\
\hline Safety & $\mathrm{NE}$ & $\mathrm{NE}$ & $\mathrm{NE}$ & $8 \%$ & $\mathrm{NE}$ & $\mathrm{NE}$ & $\mathrm{NE}$ \\
\hline Welfare facility for visitors & - & -- & $-\ldots$ & $8 \%$ & $-(0-0.96)$ & $-(1-1.9)$ & $-(2-2.9)$ \\
\hline Watching bird/live species & - & - & $\ldots$ & $10 \%$ & $-(0-1.2)$ & $-(1.32-2.4)$ & $-(2.52-3.6)$ \\
\hline Enjoying the beach area & $\mathrm{NE}$ & $\mathrm{NE}$ & $\mathrm{NE}$ & $2 \%$ & $\mathrm{NE}$ & $\mathrm{NE}$ & $\mathrm{NE}$ \\
\hline Climate & $\mathrm{NE}$ & $\mathrm{NE}$ & $\mathrm{NE}$ & $0.3 \%$ & $\mathrm{NE}$ & $\mathrm{NE}$ & $\mathrm{NE}$ \\
\hline Total change & & & & & $-(0-8.2)$ & $-(8.9-16.4)$ & - (17.2-24.7) \\
\hline
\end{tabular}

assigned in Table 5 with the 'contribution to the total value' derived from Fig. 3 and the pre-estimated 'producer surplus' value. Total change was calculated by summing the changes of producer surplus associated with each attribute, resulting in estimated losses of 0-8.2 million BDT (US\$ 0-98,400), 8.9-16.4 million BDT (US\$ 106,800-196,800), and 17.2-24.7 million BDT (US\$ 206,000-296,000) for scenarios A, B, and C, respectively.

\subsubsection{Changes in the art value}

Table 6 shows the estimation of changes in the art value of the wetland ecosystems. This analysis resulted in assigning low ranges of change to both attributes in Scenario A (0-10\%), increasing to higher losses ranging between 21 and 30\% for Scenario C in which a larger inundated area was considered.

The total loss value was calculated by multiplying the potential impact indications assigned in Table 6 with the estimated present-day value, and summing the resulting loss values of the two attributes (assuming equal contribution to the total value) for each RSLR scenario. The results indicate losses of 0-0.12 million BDT (US\$ 0-1450), 0.13-0.25 million BDT (US\$ 1550-3000), and 0.26-0.37 million BDT (US\$ 3100-4400) for scenarios A, B, and C, respectively.

\subsubsection{Changes in the value of raw materials (timber and fuelwood)}

Table 7 shows the results of this part, indicating a conservative scenario of $0-10 \%$ reduction in the value of raw materials for both Scenarios B and C, while no potential loss was considered for Scenario $A$, in which the SMF is not exposed to inundation due to $25 \mathrm{~cm}$ of RSLR by 2100 (see Fig. 2). The total loss value was calculated by multiplying the potential impact indications assigned in Table 7 with the estimated present-day value for each Scenario. The results indicate potential losses in the range of $0-85$ million BDT (US\$ $0-1,000,000$ ) for both scenarios B and C, and no expected loss for Scenario A.

\section{Discussion}

The few available case studies have quantified potential changes in the value of WES due to CC impacts by using biochemical modelling (Barange et al., 2017), and mathematical models such as SLAMM (Yoskowitz et al., 2017) and DIVAA (Roebeling et al., 2013). However, here an alternative and straight forward approach is proposed, adapted from Mehvar et al. (2018b), grounded in primary and secondary data, as well as expert opinions to estimate the likely changes of WES due to different RSLR-induced inundation in the West coast of Bangladesh in 2100.

In this study, the estimated changes in the value of four WES indicate (maximum) total potential losses in the range of US\$ 16.5-20 MM, and US\$ 0-1 MM for the services of food provision (fish and marine species), and provision of raw materials (timber and fuelwood), respectively. The estimated (maximum) losses for tourism and art services are lower in the range of US $\$ 206,000-296,000$ and US\$ $3100-4,400$, respectively. These maximum estimates represent the changes under the worst case Scenario C (with $1.77 \mathrm{~m}$ of RSLR). Table 8 provides an overview of the losses, estimated in 2017 prices, in BDT/Ha and US\$/Ha for the three considered inundation scenarios in 2100 .

Note that, given the 2100 time horizon, here a zero-discounting rate was used for all estimates, since this rate is widely accepted as a good option for long term (more than 30 years) projects with intergeneration consequences and sustainability view of the World (Voinov and Farley, 2007). However, to address the uncertainty related to discounting, a sensitivity analysis was done for the loss values of Sundarbans' WES in 2100 with four non-zero discounting factors. The results of this analysis are in line with the discourse on the discounting rates in climate change and sustainability literature (Voinov and Farley, 2007; Saez and Requena, 2007), showing that the valuation outcomes are sensitive to the choice of a discounting rate. The results of sensitivity analysis are presented in the Supplementary Material - section 2.

Existing literature on the coastal area of Bangladesh (mostly related to the SMF) provide a few differing assessments of physical CC impacts. For example, Loucks et al. (2010) reported that $28 \mathrm{~cm}$ of SLR would result in a great loss of the SMF and degradation of more than $95 \%$ of area where the tigers inhabit, while Colette (2007) suggested that global SLR of $45 \mathrm{~cm}$ will cause $75 \%$ degradation in the area of the SMF by 2100 . On the contrary, more recent studies present a different picture in which small inundation areas are attributed to projections of different SLR scenarios in Bangladesh. For example, Dasgupta et al. (2018) found that a $1.2 \mathrm{~m}$ SLR by 2100 will not inundate the core region of the Sundarbans, showing that even under the worst case SLR scenario, the Sundarbans will remain above the mean sea-level. In

Table 6

Changes in the art value due to RSLR-induced inundation by 2100 for the three scenarios (in 2017 BDT, discounting rate $\mathrm{k}=0$ ). Each - indicates a $10 \%$ decrease in the characteristics of the attributes compared to present. Negative values indicate a loss compared to the present-day.

\begin{tabular}{|c|c|c|c|c|c|c|}
\hline Art related attribute & \multicolumn{3}{|c|}{ Potential impact of inundation } & \multicolumn{3}{|c|}{ Change in the art value (MM. BDT) } \\
\hline Marine and coastal landscape & - & - - & $\ldots$ & $-(0-0.062)$ & $-(0.068-0.124)$ & $-(0.13-0.187)$ \\
\hline Total change & & & & $-(0-0.12)$ & $-(0.13-0.25)$ & $-(0.26-0.37)$ \\
\hline
\end{tabular}


Table 7

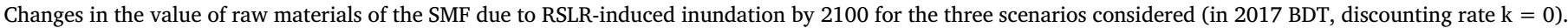
Each - indicates a $10 \%$ decrease in the value of timber and fuelwood. NE: No effect. Negative values indicate a loss compared to the present-day.

\begin{tabular}{|c|c|c|c|c|c|c|}
\hline \multirow[t]{2}{*}{ Raw materials value of the SMF (timber and fuelwood) } & \multicolumn{3}{|c|}{ Potential impact of inundation } & \multicolumn{3}{|c|}{ Change in timber \& fuelwood value (MM. BDT) } \\
\hline & Scen. A & Scen. B & Scen. C & Scen. A & Scen. B & Scen. C \\
\hline Based on market price of timber \& fuelwood & $\mathrm{NE}$ & - & - & $\mathrm{NE}$ & $-(0-85)$ & $-(0-85)$ \\
\hline Total change & & & & 0 & $-(0-85)$ & $-(0-85)$ \\
\hline
\end{tabular}

addition, Payo et al. (2016) showed that less than $10 \%$ of the present SMF area is likely to be lost as a result of different RSLR scenarios of $46 \mathrm{~cm}, 75 \mathrm{~cm}$ and $1.48 \mathrm{~m}$ by 2100 (considering combined effects of erosion and inundation). Similarly, Lovelock et al. (2015) suggested that the Sundarbans will persist beyond the year 2100 even under the most severe SLR scenario of $1.4 \mathrm{~m}$ by 2100 .

The main reason for the differing assessments in the above mentioned literature, is the usage of different DEM files, leading to different projections of inundation in the Bangladesh coastal area. In some studies, such as Payo et al. (2016) and Dasgupta et al. (2018), the DEM file was created by using the elevation data collected by FINNMAP (a Finish consultancy firm) in 1991 for the Sundarbans, while Hazra et al. (2016) used a DEM file created from the elevation data collected by the Survey of Bangladesh (SOB), Institute of Water Modelling (IWM) and CEGIS.

In our study, the most recent open-source DEM file was used, provided by USGS (2017) https://earthexplorer.usgs.gov with a spatial resolution of $30 \mathrm{~m}$ and elevation accuracy of $1 \mathrm{~m}$. The small inundated area estimated for the three scenarios considered here, is due to the relatively high elevation of the study area (especially in the SMF) which is nearly $2 \mathrm{~m}$ (and higher) above the MSL. This is in agreement with the average elevation data used in other studies such as Iftekhar and Islam (2004), Payo et al. (2016), and Hazra et al. (2016). However, a finer resolution (both vertical and spatial) DEM will provide better insights on the topography of the Western coast of Bangladesh.

The small inundated area of SMF in this study is in line with the findings of Lovelock et al. (2015), who suggests that mangrove forests are likely to persist at sites with high tidal range (here is about $4 \mathrm{~m}$ ), even with a high rate of RSLR and low level of sediment availability. Notably, the small inundation area in this study would limit landward migration of the SMF. This natural response of mangroves to inundation, can play a vital role in preserving the mangrove forests, preventing losses in the services provided by this ecosystem. It should be emphasized that, here the MSL (as zero elevation reference) was assumed to be the lowest elevation, at which mangroves can provide services, thus no expansion and recovery was considered for the submerged mangroves.

\subsection{RSLR impact assignation}

Quantitative assessment of the RSLR-induced inundation impacts on WES was based on the scenario-based approach presented by Mehvar et al. (2018b), which is grounded in primary and secondary data supported by expert opinions. This approach was considered in relation to the inundated area implying that the more the area is inundated, the higher the potential impacts will be. Notably, impact indications were applied in a range with $10 \%$ variability rather than affecting the services with a single deterministic value, which is due to the very uncertain change in future climate.

For example, a conservative impact range was considered for the provision of raw materials service of the SMF for the Scenario B and C (Table 7). Assignation of this low impact range (0-10\%) was driven by two reasons: (1) low projection of inundation shown in Fig. 2 conveys that only small parts of the SMF (about 5\%), which are adjacent to the river will be inundated, and therefore our study area is expected to be less affected by the water salinity; and (2) the Sundarbans as a multispecies forest is likely to be more resilient to SLR, due to interspecific facilitation (Huxham et al., 2010; Ward et al., 2016).

With respect to the food provision service (Table 3), the impact indications on different fish/fishery related variables, depend on whether the variables contribute to the fresh water or aquaculture-related fishery. Since it is shown (Fig. 2) that the inundation will mostly occur in the Northern part of the Sundarbans where the aquaculture-ponds are dominantly located, a higher impact indication was therefore assigned (upto $51 \%-60 \%$ for Scenario C). This is because the physical variable of fish ponds area is expected to be severely damaged and affected by the interference of salt water (Minar et al., 2013). However, for other variables, given the small inundation area, lower impact of $21 \%-30 \%$ was assigned for Scenario C.

As indicated in Table 4, a constant contribution level of $10 \%$ was assigned for most of the fishery related variables, while nursery habitat and fish ponds were weighted higher (25\%) than other attributes, and therefore contributed more to the producer surplus value. ${ }^{6}$ This would represent the weight of each fishery-related variable as a percentage of the total value of producer surplus. These percentages are approximate indications (adapted from Mehvar et al., 2018b), since there is no concrete evidence available yet to enable quantitative estimation of CC driven changes (in particular, RSLR-induced inundation) to the fishery related variables over a long time span.

To quantify potential inundation impacts on tourism service, a constant impact indication was assigned (e.g. $21 \%-30 \%$ of the estimated value in Scenario C) for the recreation-related attributes, depending on the extent of inundated area. However, the small inundated area in the Sundarbans region, especially in the Scenario A, has led us to consider a conservative range of change $(0-10 \%)$ in the recreation value of the SMF, and the marine area. This approach could be also considered as a scenario, since no data could be collected and used for such quantitative assessment.

Table 8

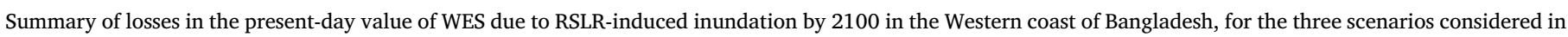
this study (in 2017 price, discounting rate $\mathrm{k}=0$ ).

\begin{tabular}{|c|c|c|c|c|c|c|}
\hline \multirow[t]{2}{*}{ WES } & \multicolumn{3}{|c|}{ Estimated losses in the value (BDT/Ha) } & \multicolumn{3}{|c|}{ Estimated losses in the value (US\$/Ha) } \\
\hline & Scen. A & Scen. B & Scen. C & Scen. A & Scen. B & Scen. C \\
\hline Food provision (fish and marine species) & $0-390$ & 985-1337 & $1655-2000$ & $0-4.7$ & $11.8-16$ & $20-24$ \\
\hline Raw materials (timber and fuelwood) & 0 & $0-225$ & $0-225$ & 0 & $0-2.7$ & $0-2.7$ \\
\hline Recreation/Tourism & $0-9$ & $10.7-19.5$ & $20.7-30$ & $0-0.11$ & $0.12-0.23$ & $0.25-0.36$ \\
\hline Art & $0-0.14$ & $0.15-0.3$ & $0.31-0.44$ & $0-0.001$ & $0.001-0.003$ & $0.003-0.005$ \\
\hline
\end{tabular}




\subsection{Exclusion of estimating consumer surplus in quantifying present-day value of tourism service}

To estimate the present-day value of tourism service, we attempted to use the contingent valuation method to calculate the consumer surplus value. In order to do so, it was aimed to elicit visitors' willingness to pay to conserve the coastal environment of Western Bangladesh, and to not lose the recreational attributes associated with its ecosystems. However, the respondents stated that they can not afford any monetary contribution, and even if it is affordable, they were not willing to pay, since they believe that they are not responsible for the damages to the coastal wetlands and associated ecosystems in Western Bangladesh. Because of this reluctance observed in the interviews, calculation of consumer surplus value was excluded from the valuation study (step 1), and tourism value of wetland ecosystems was therefore based on the net revenue generated by the visitors (producer surplus).

\subsection{The likely factors affecting the results}

Apart from the likely changes of future climate and its impacts on coastal wetlands, many factors such as anthropogenic and non CC-related factors may also affect coastal and marine ecosystems and the outcomes of this study. For example, construction of coastal protection structures, human-induced water pollutions, changes in tourist expenditure, sample size, market price of fish or timber, types of mangrove species, income and its distribution, expert opinions, ecological responses, and even social norms will likely change these estimates by the year 2100. Our sensitivity analysis (presented in the Supplementary material) indicates that the discounting rate remarkably affects the results in the expected direction. Given the long-term horizon for this WES valuation, to avoid placing less importance on the future RSLRinduced inundation in Bangladesh, zero-discounting rate was used as the base case for reporting our results. This is in line with the statement of Voinov and Farley (2007), conveying that catastrophic events occurring far enough in the future (e.g. global warming) can be treated as essentially irrelevant today, (even) if a very low discounting rate is considered.

\subsection{Relevance of this study to the current conflicts in management of the Sundarbans region}

The western coastal area of Bangladesh, and in particular, the Sundarbans mangrove forest has historically been the subject of environmental conflicts leading to the degradation of this coastal ecosystem (Aziz and Paul, 2015). For example, the extent of the SMF in Bangladesh has been reduced due to a decrease in sediment-laden freshwater discharge through the river system since the 1975 commissioning of the Farakka Barrage in India (Aziz and Paul, 2015). This degradation has resulted in losses of plant species such as Heritiera fomes (sundri) which is one of the most commercially important plants. According to Aziz and Paul (2015), other conflicts leading to the degradation of the SMF include over-harvesting by grazing, fishing, pollution, reduction of silt deposition, and coastal hazards (e.g. erosion, tropical cyclones and tsunamis). In addition, expansion of shrimp farming in Sundarbans (in an unplanned way) due to extremely low shrimp farming costs, has transformed some areas of the SMF that provides valuable ecosystem services, into private aquaculture lands that only contributes to the food provision service (Shahid and Islam, 2003; Afroz and Alam, 2012). Such schemes do not consider the longterm sustainability of coastal resources.

Apart from the factors mentioned above, there is a conflict between

\footnotetext{
${ }^{6}$ Such a higher contribution level for fish ponds and fishing community may not be justifiable at locations where the fishery industry is not as aquaculturedependent as it is in the Sundarbans region.
}

Sundarbans forest officials and fishermen which has led to the establishment of wildlife sanctuary for fishermen (Ghosh, 2015). This conflict highlights the issue of balancing biodiversity conservation, while still providing a livelihood to the Sundarbans local community (Ghosh, 2015).

From a broader perspective, many international conservation agreements have been signed between Bangladesh and India providing legal frameworks to protect the SMF, but their implementation is still suffering from some limitations (Iftekhar, 2010). Some of these limitations include the lack of a comprehensive environmental impact assessment for the SMF, activities associated with resource extraction, and conflict between trade and export policies.

The results of this study can address some of the conflicts mentioned above and facilitate the sustainability of the SMF and the services that this wetland ecosystem provides. This can be done by: (1) communicating the value of SMF services estimated (tourism, art, food provision, provision of raw materials), and raising the local community awareness on the economic contribution of these services to their benefits; and (2) encouraging public participation for supporting environmental conservation schemes in the Sundarbans region. The results of this study can also: (1) provide better insights for decision/ policy makers on how vulnerable the region is to climate change-driven hazards (in particular to RSLR-induced inundation with different possible 2100 scenarios), and to what extent the value of the selected SMF services is likely to decrease in a long time span; and (2) help decision makers to reach a compromise between the SMF conservation schemes and land conversion plans for aquaculture purposes which need a collaborative approach towards addressing the issue of sustainable utilization practices. The outcomes can also contribute to future environmental impacts assessment in Sundarbans by highlighting the potential losses in the value of ecosystem services as estimated here for the food provision, tourism, and art services.

\section{Conclusion}

In this study, potential changes in the value of ecosystem services due to RSLR-induced inundation were estimated for three scenarios by 2100 in the wetlands along the Western coastal area of Bangladesh. To this end, a three-step approach was used, in which economic valuation techniques were combined with a scenario-based approach. This approach was here applied to quantify potential losses in the value of four WES; food provision (fish and marine species), tourism, art and provision of raw materials (timber and fuelwood) which are provided by the SMF, aquaculture lands, and neritic system (Bay of Bengal). The monetization of WES was done by using a combination of contingent valuation, market price and net factor income techniques, based on the original field work undertaken in this study in 2017 in Western Bangladesh.

The results revealed low to medium changes in the value of services provided by the wetland ecosystems for all the three considered inundation scenarios; Scenario A with $0.25 \mathrm{~m}$ of RSLR, Scenario B with $1.18 \mathrm{~m}$ of RSLR, and Scenario C with $1.77 \mathrm{~m}$ of RSLR. The results represented maximum potential losses of $5 \%, 16 \%$ and $17 \%$ of the present-day value of raw materials, food provision and recreation services respectively, for the worst case inundation scenario (C). Notably, the results showed that, the loss associated with art value is likely to be higher at $40 \%$ of its present-day value for the same scenario.

The outcomes of this study are expected to provide a better insight to the little known issue of quantifying CC driven changes to the coastal WES, evidence for which is scarce in the current literature. Such quantitative assessment is of high importance, especially in Bangladesh and other developing countries where the flood resilience is not enough to properly cope with the rapid pace of CC impacts on the coastal wetland ecosystems in such data-scarce environments. 


\section{Acknowledgements}

The authors are thankful for the financial support from the AXA Research Fund and the Ministry I\&M-IHE Delft cooperation program. RR is supported by the AXA Research fund and the Deltares Strategic Research Programme 'Coastal and Offshore Engineering'. The authors would also like to thank the anonymous reviewers for their very constructive comments which helped improve the manuscript greatly.

\section{Appendix A. Supplementary data}

Supplementary data to this article can be found online at https:// doi.org/10.1016/j.ocecoaman.2018.12.009.

\section{References}

Adger, W.N., Hughes, T.P., Folke, C., Carpenter, S.R., Rockström, J., 2005. Social-ecological resilience to coastal disasters. Science 309 (5737), 1036-1039.

Aerts, J.C., Botzen, W.W., Emanuel, K., Lin, N., de Moel, H., Michel-Kerjan, E.O., 2014 Evaluating flood resilience strategies for coastal megacities. Science 344 (6183), 473-475.

Afroz, T., Alam, S., 2012. Sustainable shrimp farming in Bangladesh: a quest for an integrated coastal zone management. Ocean Coast. Manag. 71, 275-283.

Ali, S., 1994. Sundarbans: its resources and ecosystem. In: Paper Presented at the Proceedings of the National Seminar on Integrated Management of Ganges Flood Plains and Sundarbans Ecosystem, vol. 1618. Khulna University, Khulna, Bangladesh, pp. 3849.

Aziz, A., Paul, A., 2015. Bangladesh Sundarbans: present status of the environment and biota. Diversity 7 (3), 242-269.

Barange, M., Butenschön, M., Yool, A., Beaumont, N., Fernandes, J.A., Martin, A.P., Allen, J., 2017. The cost of reducing the North Atlantic Ocean biological carbon pump. Front. Mar. Sci. 3, 290.

Belton, B., Azad, A., 2012. The characteristics and status of pond aquaculture in Bangladesh. Aquaculture 358, 196-204.

Biswas, S.R., Choudhury, J.K., Nishat, A., Rahman, M.M., 2007. Do invasive plants threaten the Sundarbans mangrove forest of Bangladesh? For. Ecol. Manag. 245 (1-3), 1-9.

Brown, S., Nicholls, R., 2015. Subsidence and human influences in mega deltas: the case of the Ganges-Brahmaputra-Meghna. Sci. Total Environ. 527, 362-374.

Chaffey, D.R., Miller, F., Sandom, J., 1985. A Forest Inventory of the Sundarbans, Bangladesh. Main Report. Overseas Development Administration, London, pp. 196.

Chand, B., Trivedi, R., Biswas, A., Dubey, S., Beg, M., 2012. Study on impact of saline water inundation on freshwater aquaculture in Sundarban using risk analysis tools. Explor. Anim. Med. Res. 2, 170-178.

Cheung, W.W., Dunne, J., Sarmiento, J.L., Pauly, D., 2011. Integrating ecophysiology and plankton dynamics into projected maximum fisheries catch potential under climate change in the Northeast Atlantic. ICES J. Mar. Sci. 68 (6), 1008-1018.

Cochrane, K., De Young, C., Soto, D., Bahri, T., 2009. Climate change implications for fisheries and aquaculture. In: FAO Fisheries and aquaculture technical paper, vol. 530. pp. 212.

Colette, A., 2007. Case Studies on Climate Change and World Heritage. UNESCO World Heritage Centre, Paris, France, pp. 79.

Das, S., Siddiqi, N., 1985. The Mangroves and Mangrove Forests of Bangladesh. BulletinBangladesh Forest Research Institute. Mangrove Silviculture Division, Bangladesh no. 2.

Dasgupta, S., Huq, M., Mustafa, M.G., Sobhan, M.I., Wheeler, D., 2017. The impact of aquatic salinization on fish habitats and poor communities in a changing climate: evidence from southwest coastal Bangladesh. Ecol. Econ. 139, 128-139.

Dasgupta, S., Huq, M., Sobhan, I., Wheeler, D., 2018. sea-level rise and species conservation in Bangladesh's Sundarbans region. J. Manag. Sustain. 8 (1), 1.

de Moel, H., Jongman, B., Kreibich, H., Merz, B., Penning-Rowsell, E., Ward, P.J., 2015. Flood risk assessments at different spatial scales. Mitig. Adapt. Strategies Glob. Change 20 (6), 865-890.

Denissen, A.K., 2012. Climate Change and its Impacts on Bangladesh. Available. http:// www.ncdo.nl/artikel/climate-change-its-impacts-bangladesh, Accessed date: 20 November 2017.

DOF, 2010. Fisheries Statistical Year Book of Bangladesh 2008-2009, vol. 26 Fisheries Resource Survey System, Department of Fisheries, Ministry of Fisheries and Livestock No. 1.

Ghosh, P., 2015. Conservation and conflicts in the Sundarban biosphere reserve, India. Geogr. Rev. 105 (4), 429-440.

Giri, C., Pengra, B., Zhu, Z., Singh, A., Tieszen, L.L., 2007. Monitoring mangrove forest dynamics of the Sundarbans in Bangladesh and India using multi-temporal satellite data from 1973 to 2000. Estuar. Coast. Shelf Sci. 73 (1-2), 91-100.

Goldes, S.A., Ferguson, H.W., Moccia, R.D., Daoust, P.Y., 1988. Histological effects of the inert suspended clay kaolin on the gills of juvenile rainbow trout, Salmo gairdneri Richardson. J. Fish. Dis. 11 (1), 23-33.

Harley, C.D., Randall Hughes, A., Hultgren, K.M., Miner, B.G., Sorte, C.J., Thornber, C.S., Rodriguez, L.F., Tomanek, L., Williams, S.L., 2006. The impacts of climate change in coastal marine systems. Ecol. Lett. 9 (2), 228-241.

Henley, W.F., Patterson, M.A., Neves, R.J., Lemly, A.D., 2000. Effects of sedimentation and turbidity on lotic food webs: a concise review for natural resource managers. Rev. Fish. Sci. 8 (2), 125-139.

Hazra, S., Mukhopadhyay, A., Chanda, A., Mondal, P., Ghosh, T., Mukherjee, S., Salehin, M., 2016. Characterizing the 2D shape complexity dynamics of the islands of Sundarbans, Bangladesh: a fractal dimension approach. Environ. Earth Sci. 75 (20), 1367.

Hoegh-Guldberg, O., Mumby, P.J., Hooten, A.J., Steneck, R.S., Greenfield, P., Gomez, E., Harvell, C.D., Sale, P.F., Edwards, A.J., Caldeira, K., Knowlton, N., 2007. Coral reefs under rapid climate change and ocean acidification. Science 318 (5857), 1737-1742.

Hossain, A.N.M., Lynam, A.J., Ngoprasert, D., Barlow, A., Barlow, C.G., Savini, T., 2018. Identifying landscape factors affecting tiger decline in the Bangladesh Sundarbans. Glob. Ecol. Conserv. 13.

Huxham, M., Kumara, M.P., Jayatissa, L.P., Krauss, K.W., Kairo, J., Langat, J., Mencuccini, M., Skov, M.W., Kirui, B., 2010. Intra-and interspecific facilitation in mangroves may increase resilience to climate change threats. Phil. Trans. Biol. Sci. 365 (1549), 2127-2135.

Iftekhar, M., 1999. Vegetation Dynamics in the Sundarbans and the Contribution of Salinity between 1985-1995. B. Sc. Thesis, Forestry and Wood Technology Discipline. Khulna University, Khulna, Bangladesh.

Iftekhar, M., Islam, M., 2004. Degeneration of Bangladesh's Sundarbans mangroves: a management issue. Int. For. Rev. 6 (2), 123-135.

Iftekhar, M.S., 2010. Protecting the Sundarbans: An appraisal of national and international environmental laws. Asia Pac. J. Envtl. L 13, 249.

IHE, 2016. Relative Sea Level Rise Scenarios along the Central Coast of Bangladesh.

Islam, S.D.U., Bhuiyan, M.A.H., 2018. Sundarbans mangrove forest of Bangladesh: causes of degradation and sustainable management options. Environ. Sustain. 1-19.

Kuhfuss, L., Rey-Valette, H., Sourisseau, E., Heurtefeux, H., Rufray, X., 2016. Evaluating the impacts of sea level rise on coastal wetlands in Languedoc-Roussillon, France. Environ. Sci. Pol. 59, 26-34.

Loucks, C., Barber-Meyer, S., Hossain, M.A.A., Barlow, A., Chowdhury, R.M., 2010. Sea level rise and tigers: predicted impacts to Bangladesh's Sundarbans mangroves. Climatic Change 98 (1-2), 291.

Lovelock, C.E., Cahoon, D.R., Friess, D.A., Guntenspergen, G.R., Krauss, K.W., Reef, R., Rogers, K., Saunders, M.L., Sidik, F., Swales, A., 2015. The vulnerability of IndoPacific mangrove forests to sea-level rise. Nature 526 (7574), 559-563.

MAB (Multi-AgencyBrief), 2009. Fisheries and Aquaculture in a Changing Climate, vol. 6 FAO, Rome, Italy.

Mahadevia, K., Vikas, M., 2012. Climate change-impact on the Sundarbans. Int. Sci. J. Environ. Sci. 7-15.

Mehvar, S., Filatova, T., Dastgheib, A., de Ruyter van Steveninck, E., Ranasinghe, R., 2018a. Quantifying economic value of coastal ecosystem services: a review. J. Mar. Sci. Eng. 6 (1), 5.

Mehvar, S., Filatova, T., Syukri, I., Dastgheib, A., Ranasinghe, R., 2018b. Developing a framework to quantify potential Sea level rise-driven environmental losses: a case study in Semarang coastal area, Indonesia. Environ. Sci. Pol. 89, 216-230.

Minar, M., Hossain, M.B., Shamsuddin, M., 2013. Climate change and coastal zone of Bangladesh: vulnerability, resilience and adaptability. Middle East J. Sci. Res. 13 (1), 114-120.

Mohanty, B., Mohanty, S., Sahoo, J., Sharma, A., 2010. Climate Change: Impacts on Fisheries and Aquaculture Climate Change and Variability. InTech.

Mondal, S.H., Debnath, P., 2017. Spatial and temporal changes of Sundarbans reserve forest in Bangladesh. Environ. Nat. Resour. J. 15 (1), 51-61.

Nicholls, R.J., 2004. Coastal flooding and wetland loss in the 21st century: changes under the SRES climate and socio-economic scenarios. Global Environ. Change 14 (1), 69-86.

Nicholls, R.J., 2015. Adapting to Sea Level Rise Coastal and Marine Hazards, Risks, and Disasters. Elsevier, pp. 243-270.

Nicholls, R.J., Cazenave, A., 2010. Sea-level rise and its impact on coastal zones. Science 328 (5985), 1517-1520.

Payo, A., Mukhopadhyay, A., Hazra, S., Ghosh, T., Ghosh, S., Brown, S., Nicholls, R.J., Bricheno, L., Wolf, J., Kay, S., Lázár, A.N., Haque, A., 2016. Projected changes in area of the Sundarban mangrove forest in Bangladesh due to SLR by 2100. Climatic Change 139 (2), 279-291.

Peñuelas, J., Sardans, J., Filella, I., Estiarte, M., Llusià, J., Ogaya, R., Carnicer, J., Bartrons, M., Rivas-Ubach, A., Grau, O., Peguero, G., Margalef, O., Pla-Rabés, S., Stefanescu, C., Asensio, D., Preece, C., Liu, L., Verger, A., Rico, L., Barbeta, A., Achotegui-Castells, A., Gargallo-Garriga, A., Sperlich, D., Farré-Armengol, G., Fernández-Martínez, M., Liu, D., Zhang, C., Urbina, I., Camino, M., Vives, M., NadalSala, D., Sabaté, S., Gracia, C., Terradas, J., 2017. Assessment of the impacts of climate change on Mediterranean terrestrial ecosystems based on data from field experiments and long-term monitored field gradients in Catalonia. Environ. Exp. Bot. 152, 49-59.

Pernetta, J.C., 1992. Impacts of climate change and sea-level rise on small island states: national and international responses. Global Environ. Change 2 (1), 19-31.

Portner, H.O., Knust, R., 2007. Climate change affects marine fishes through the oxygen limitation of thermal tolerance. Science 315 (5808), 95-97.

Rahman, M., 2003. Invasive Plants of Sundarbans. Interim Report under SBCP Project. IUCN, Bangladesh, pp. 32.

Roebeling, P., Costa, L., Magalhães-Filho, L., Tekken, V., 2013. Ecosystem service value losses from coastal erosion in Europe: historical trends and future projections. J. Coast. Conserv. 17 (3), 389-395.

Roy, A.K.D., Alam, K., Gow, J., 2013. Community perceptions of state forest ownership and management: a case study of the Sundarbans Mangrove Forest in Bangladesh. J. Environ. Manag. 117, 141-149.

Roy, K., Gain, A.K., Mallick, B., Vogt, J., 2017. Social, hydro-ecological and climatic change in the southwest coastal region of Bangladesh. Reg. Environ. Change 17 (7), 
1895-1906.

Saez, C.A., Requena, J.C., 2007. Reconciling sustainability and discounting in Cost-Benefit Analysis: a methodological proposal. Ecol. Econ. 60 (4), 712-725.

Scavia, D., Field, J.C., Boesch, D.F., Buddemeier, R.W., Burkett, V., Cayan, D.R., Fogarty, M., Hartwell, M.A., Howarth, R.W., Mason, C., Reed, D.J., Royer, T.C., Sallenger, A.H., Titus, J.G., 2002. Climate change impacts on US coastal and marine ecosystems. Estuaries 25, 149-164.

Schep, S., Johnson, A., van Beukering, P., Wolfs, E., 2012. The Fishery Value of Coral Reefs in Bonaire. Applying Various Valuation Techniques. IVM Institute for Enironmental Studies, Amsterdam, The Netherlands.

Schep, S., van Beukering, P., Brander, L., Wolfs, E., 2013. The Tourism Value of Nature on Bonaire Using Choice Modelling and Value Mapping. IVM Institute for Environmental Studies, Amsterdam, The Netherlands.

Shahid, M.A., Islam, J., 2003. Impact of denudation of mangrove forest due to shrimp farming on coastal environment in Bangladesh. In: Wahab, M.A. (Ed.), Environmental and Socio-economic Impacts of Shrimp Farming in Bangladesh. Bangladesh Centre for Advanced Studies (BCAS), Dhaka, pp. 49-60.

Spalding, M.D., Ruffo, S., Lacambra, C., Meliane, I., Hale, L.Z., Shepard, C.C., Beck, M.W., 2014. The role of ecosystems in coastal protection: adapting to climate change and coastal hazards. Ocean Coast. Manag. 90, 50-57.

Sumaila, U.R., Cheung, W.W., Lam, V.W., Pauly, D., Herrick, S., 2011. Climate change impacts on the biophysics and economics of world fisheries. Nat. Clim. Change 1 (9), 449-456.

Uddin, M.S., van Steveninck, E. d. R., Stuip, M., Shah, M.A.R., 2013. Economic valuation of provisioning and cultural services of a protected mangrove ecosystem: a case study on Sundarbans Reserve Forest, Bangladesh. Ecosyst. Serv. 5, 88-93.
USGS (U.S. Geological Survey), 2017. Earth explorer. Available: http://earthexplorer. usgs.gov, Accessed date: 18 November 2017.

Van Beukering, P., Wolfs, E., 2012. Essays on Economic Values of Nature of Bonaire. A Desk Study. Institute for Environmental Studies, VU University Amsterdam, the Netherlands IVM report (W12-14): 2012.

Van de Kerkhof, S., Schep, S., van Beukering, P., Brander, L., Wolfs, E., 2014b. The Tourism Value of Nature on St Eustatius.

Voinov, A., Farley, J., 2007. Reconciling sustainability, systems theory and discounting. Ecol. Econ. 63 (1), 104-113.

Ward, R.D., Friess, D.A., Day, R.H., MacKenzie, R.A., 2016. Impacts of climate change on mangrove ecosystems: a region by region overview. Ecosyst. Health Sustain. 2 (4).

Waters, T.F., 1995. Sediment in sreams: sources, biological effects and controls. Am. Fish. Soc. Monogr. 7.

Weisse, R., Bellafiore, D., Menéndez, M., Méndez, F., Nicholls, R.J., Umgiesser, G. Willems, P., 2014. Changing extreme sea levels along European coasts. Coast. Eng. 87, 4-14.

Williams, L., Rota, A., 2010. Impact of Climate Change on Fisheries and Aquaculture in the Developing World and Opportunities for Adaptation. Fisheries Thematic Paper: Tool for Project Design.

Yang, S.C., Shih, S.S., Hwang, G.W., Adams, J.B., Lee, H.Y., Chen, C.P., 2013. The salinity gradient influences on the inundation tolerance thresholds of mangrove forests. Ecol. Eng. 51, 59-65.

Yoskowitz, D., Carollo, C., Pollack, J.B., Santos, C., Welder, K., 2017. Integrated ecosystem services assessment: valuation of changes due to sea level rise in Galveston Bay, Texas, USA. Integrated Environ. Assess. Manag. 13 (2), 431-443. 